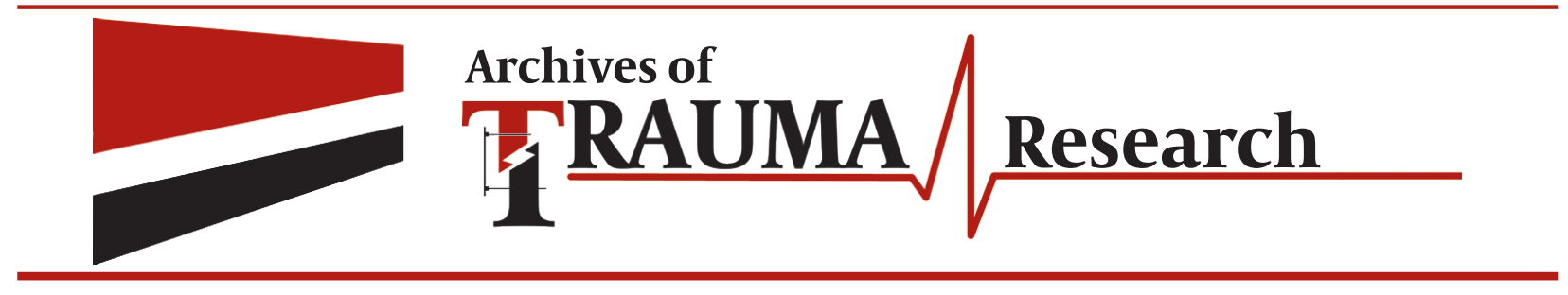

\title{
National Trauma Registry Center, as a Backbone of Trauma Management and Research
}

\author{
Mohammad Hossein Ebrahimzadeh ${ }^{{ }^{*}}$ \\ ${ }^{1}$ Trauma Research Center, Mashhad University of Medical Sciences, Mashhad, IR Iran
}

\begin{tabular}{l}
\hline A R T I C L E I N F O \\
\hline Article type: \\
Editorial \\
\hline Article history: \\
Received: 08 Oct 2012 \\
Revised:10 Oct 2012 \\
Accepted: 15 Oct 2012 \\
\hline
\end{tabular}

\section{Keywords:}

Wound and Injury

Trauma Management

Research

We are living in an era of growing incidence of trauma, violence and disasters around the world. In addition to raising of high velocity of vehicle accident injuries, we encounter many environmental disasters and military conflicts in the Middle East and Asia region. Currently, road traffic trauma is the 6th most common cause of death in developing countries and according to the WHO (World Health Organization) it will be placed at the 3rd leading cause of mortality and morbidity by $2030(1,2)$. While the mortality rate caused by trauma is almost doubled in our region compared to Western countries, disability from injury is much more common in comparison (3). According to the reports of the World Health Organization, among fatality causes in Iran, the road accidents is ranked the second cause of death and cover $11 \%$ of fatalities and $16 \%$ of years of life lost (YLL) due to a sudden death $(4,5)$. This is the tip of the iceberg of trauma, and there are a number of problems which are related to injury. There are various kinds of occupational, household,
Implication for health policy/practice/research/medical education:

Today we are facing with an increasing number of multiple trauma patients resulting from vehicle accidents, disasters and wars so a need for a National Registry for Trauma is evident. This center will help health service policies, medical education and clinical researches.

- Please cite this paper as:

Ebrahimzadeh MH. National Trauma Registry Center, as a Backbone of Trauma Management and Research. Arch Trauma Res. 2012:1(3): 87-8. DOI: 10.5812/atr.8487

Published by Kowsar, 2012. cc 3.0.

sport, assault, contact etc. injuries, which we have only scattered the data published occasionally and based on available cases and with very different background of the authors. There are also problems in transportation and admission of the cases to appropriate hospitals with supporting services that could manage these specific groups of the patients. Another significant problem is the overall condition of the referral centers considering the availability of modern equipment and skilled personnel. The evaluation of early and late complications of the injured patients and their final outcomes at the time of discharge and even after a while is another deficiency of our health care service for the injured people. Adding to this complexity there are some specific cultural and perhaps environmental types of injuries that are not common in other societies. The need for special consideration to the aforementioned problems as well as organizing and objectively oriented domestic researches in the fields of epidemiology management, estimation of disabilities, mor-

\footnotetext{
* Corresponding author: Mohammad Hossein Ebrahimzadeh, Orthopedic and Trauma Research Center, Mashhad University of Medical Sciences, Mashhad, IR Iran.Tel.:+98-5118012610, Fax:+98-5118417453, E-mail: ebrahimzadehmh@mums.ac.ir. () 2012, Kashan University of Medical Sciences; Published by Kowsar

This is an open-access article distributed under the terms of the Creative Commons Attribution License (http://creativecommons.org/licenses/by/3.0), which permits unrestricted use, distribution, and reproduction in any medium, provided the original work is properly cited.
} 
talities and burden on the economy of the country is now obviously evident more than any other times. Basically, it seems that the presence of an academic national registry center as an infrastructure vital coordinating center to all data related to trauma and its consequences from different organizations including police, fire fighting, services, emergency medical services, health care service system and forensic medicine organization. Such a trauma registry center can provide applicable information for health care administrators, health education authorities, insurance companies, clinicians and researchers which are involved in handling of different aspects of trauma. The pre-requisite of such a registry center foundation in Iran is to settle a national campaign for arrangement of both legislative and executive supports.

\section{References:}

1. WHO. The Global Burden of Disease. 2004 [updated 2008]; Available from: http://www.who.int/healthinfo/global_burden_disease/GBD_report_2004update_full.pdf.

2. Mathew G, Hanson BP. Global burden of trauma: Need for effective fracture therapies. Indian J Orthop. 2009;43(2):111-6.

3. Saadat S, Soori H. Epidemiology of traffic injuries and motor vehicles utilization in the capital of Iran: a population based study. BMC Public Health. 2011;11:488.

4. Ayati E, Behnood HR. The Burden of Fatalities Resulting from Road Accidents: An Epidemiological Study of Iran; The 14th International Conference "Road Safety on Four Continents".14-16 Nov 2007; Bangkok, Thailand.

5. Peden M, Scurfield R, Sleet D. World Report on Road Traffic Injury Prevention. Geneva: World Health Organization; 2004. 